\title{
THE RELATIONSHIP BETWEEN FASTING BLOOD GLUCOSE LEVEL AND RESTING HEART RATE IN PATIENTS WITH TYPE 2 DIABETES MELLITUS AT RADEN MATTAHER HOSPITAL, JAMBI
}

\author{
Norma Junita, Mila Citrawati, Fajriati Zulfa \\ Faculty of Medicine, UPN “Veteran” Jakarta
}

\begin{abstract}
Background: People with high resting heart rate (RHR) had higher cardiovascular impairment risk. Several studies had found the role of RHR in predicting the incidence and mortality of cardiovascular disease. Meanwhile, hyperglycemia in diabetes caused oxydative stress and inflammation which could induce sympatoexcitation and increase RHR. This study aimed to determine the relationship between fasting blood glucose level and resting heart rate in patients with type 2 diabetes mellitus at Raden Mattaher Hospital, Jambi.

Subjects and Method: This was a cross sectional study conducted at Raden Mattaher Hospital, Jambi. A total of 29 total patients with type 2 diabetes mellitus was selected for this study. The dependent variable was resting heart rate. The independent variable was fasting blood glucose level. Data was collected by a set of questionnaire. The correlation between variables analyzed by Pearson correlation.

Results: Fasting blood glucose had mean $=187.45$ and $\mathrm{SD}=7.28$. Resting heart rate frequency had mean $=95.21$ and $\mathrm{SD}=2.57$. Fasting blood glucose was correlated with resting heart rate frequency, and it was statistically significant $(r=0.47 ; p=0.009)$.

Conclusion: Fasting blood glucose is correlated with resting heart rate frequency.
\end{abstract}

Keywords: fasting blood glucose, RHR, type 2 DM

Correspondence:

Mila Citrawati. Faculty of Medicine, UPN “Veteran”, Jakarta. Email: milacitra@gmail.com. Mobile: 081282990515. 